ORIGINAL ARTICLE

\title{
Families affected by deafness: hospital services uptake in a multiethnic population
}

\author{
S Y Yoong, R Feltbower, N Spencer, P A McKinney
}

Arch Dis Child 2005;90:454-459. doi: 10.1136/adc.2003.046631

See end of article for authors' affiliations

.....................

Correspondence to: Dr S Y Yoong, Consultant Community Paediatrician, St Luke's Hospital, Bradford BD5 ONA, UK; soo.yoong@

bradfordhospitals.nhs.uk

Accepted 30 May 2004

\begin{abstract}
Aims: To examine the uptake of relevant hospital services by families with deaf children and to compare use of these services between Pakistani and white families.

Methods: A total of 214 deaf children with amplification aids who attended their paediatric outpatient and school medical appointments from October 2000 to March 2003 were studied in an observational cohort study.

Results: The demographic profile of both the Pakistani and white families was similar. Pakistani children had a statistically significant excess of the following risk factors: consanguineous marriages $186.4 \%$ Pakistani, 1.5\% white), family history of deafness (66.4\% Pakistani, 38.8\% white), and family size (birth order $>5$ : $12.8 \%$ Pakistani: $4.5 \%$ white). White children were more likely to have had post-meningitis deafness (1.4\% Pakistani, $13.4 \%$ white) and congenital infections, or have dysmorphic features $15.0 \%$ Pakistani, 13.4\% white). Overall the uptake of relevant hospital services by Pakistani and white families was very similar irrespective of an early or late diagnosis. There was an increased likelihood of white families declining cochlear implantation (17.6\% Pakistani, $75.0 \%$ white).

Conclusions: This study did not show significant differences in hospital service uptake despite different risk profiles for childhood deafness for both Pakistani and white families in Bradford. Among specialist services offered, cochlear implantation was more likely to be accessed by Pakistani families.
\end{abstract}

$$
\text { L }
$$

ittle research has been carried out on the minority ethnic deaf children. Previous studies ${ }^{1-3}$ report barriers to access o services for deaf minority ethnic families and the need for improved service provision. Bradford has a very diverse community of people from different ethnic backgrounds, including one of the largest concentrations of Muslims originating from rural Pakistan. Two studies ${ }^{45}$ carried out in Bradford found this minority ethnic community to have a high prevalence of permanent childhood hearing loss. The prevalence rates were reported to be 2.6/1000 for Asian children and 0.7/1000 for non-Asian children in 1981; 4.69/ 1000 Asian births and 1.38/1000 non-Asian births in 1990 . Bradford Maternity Unit serves a multicultural population with approximately 5500 births per year. Thirty per cent of deliveries at the maternity unit were to Asian mothers in $1990^{5}$ and by 2001 , this had increased to $45 \%$, of which $41.4 \%$ live births were Pakistani babies. ${ }^{6}$ This percentage is increasing by $1-2 \%$ each year. There was also anecdotal reporting from health professionals of a high level of late diagnosis of hearing loss among Pakistani families compared to nonAsian families.

Following a critical review ${ }^{7}$ of the role of neonatal hearing screening, commissioned by the Department of Health in 1997, the UK is moving towards implementation of a universal neonatal hearing screening programme. This service will replace a targeted screening programme restricted to those infants at high risk of congenital deafness. Bradford was successful in becoming a pilot site to introduce universal neonatal screening for congenital deafness in March 2002.

Set against this background we aimed to determine whether families from different ethnic groups differed in their uptake of the available services for deaf children in Bradford.

\section{METHODS}

This project was an observational cohort study conducted within Bradford Teaching Hospitals NHS Trust and approved by the Bradford Local Research Ethics Committee.
The flowchart in fig 1 describes the patient journey after being referred to the Paediatric Audiology Service for diagnosis and subsequent care pathway after confirmation of permanent hearing loss. In Bradford all hearing assessments are carried out by audiological scientists who notify all other appropriate professionals of any newly diagnosed patients. Current local policy and practice involve offering these families appointments with the designated paediatrician and ENT surgeon.

Subjects for the study were recruited from a cohort of children aged 0-19 years whose diagnostic audiological evaluations confirmed sensorineural hearing impairment and were fitted with hearing aids. The sampling of the study subjects (fig 2) shows that 214 subjects attended paediatric outpatient and school medical appointments from October 2000 to March 2003. During each consultation relevant information was obtained from their medical history, supplemented by audiological evaluation reports, hospital notes, and child health and/or school health records. The data were abstracted onto a standard proforma and entered into a computerised database (Access). The following information was collected:

- Demographic details of the child, including postcode of residence

- Ethnic groups as defined by $\mathrm{ONS}^{8}$

- Detailed medical history

- Late diagnosis of hearing loss (defined as diagnosis made after 6 months of age or more than six weeks after being fit to test)

- Consanguinity, which refers to marriages of parents with a recent common ancestor. ${ }^{9}$ The relationship of the parents was defined as consanguineous if they reported first and second degree cousins

- Degree of severity of hearing loss, defined as mild (20-40 dbHL), moderate (4l-70 dbHL), severe (71-95 dbHL), or profound $(>95 \mathrm{dbHL})^{10}$ 
- Presence of recognised risk factors that identify those infants who were at risk of hearing loss. ${ }^{11}$ These are: (1) family history of deafness and (2) post-meningitis children who have been deafened prelingually or postlingually. Studies indicate that $6 \%$ of all childhood hearing impairment is due to bacterial meningitis. These are a highly successful group of cochlear implantees. ${ }^{12}$ (3) Admission to neonatal intensive care unit (NICU)/special care baby unit (SCBU) for more than 48 hours. (4) congenital infections and dysmorphic appearance. The small number of children at risk of hearing loss for specific factors relating to neonatal complications, congenital infections, syndromes, or dysmorphic features associated with deafness were aggregated accordingly for analysis purposes

- All subject families were given information on the guidelines for aetiological investigation issued by professional bodies $^{13}{ }^{14}$ and the role of the clinical genetics service in provision of more information about the possible cause of their child's deafness and chance of recurrence within the family and their relatives. These services were systematically offered to each child as recommended in the guidelines. The family preferences and actions in terms of what hospital services they had already taken up and other relevant services they were ready and able to accept or decline were recorded accordingly. These were use of amplification aids (audiology), genetic counselling service, aetiological investigation of hearing loss in children, attendance at ENT, cochlear implant, and ophthalmic clinics.

Data on ethnic group were available for all subjects as shown in table 1. Due to the small number of ethnic subjects categorised as "other", they were excluded from analysis $(\mathrm{n}=7)$. These included black, mixed race, Bangladeshi, and Indian children. Differences in service uptake were compared between Asian (Pakistani) and white patients using the $\chi^{2}$ test or Fisher's Exact test depending on the expected number of subjects within each cell. The level of significance was set at $5 \%$.

\section{RESULTS}

According to our definition approximately $65 \%$ of all children known to have sensorineural hearing impairment were included. Ethnicity data were available for all subjects. Table 1 shows the profiles of the study subjects are similar regardless of ethnicity.

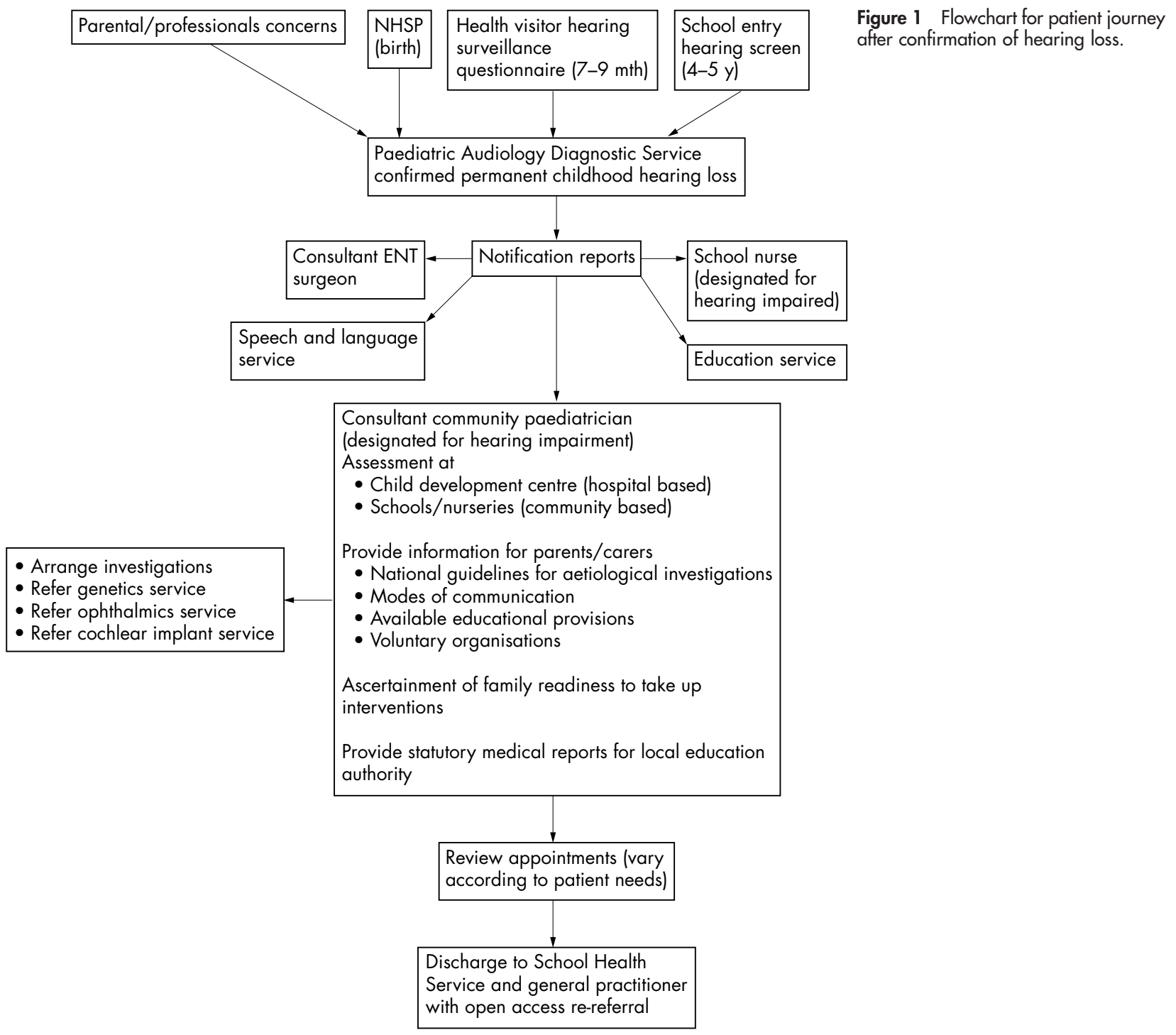




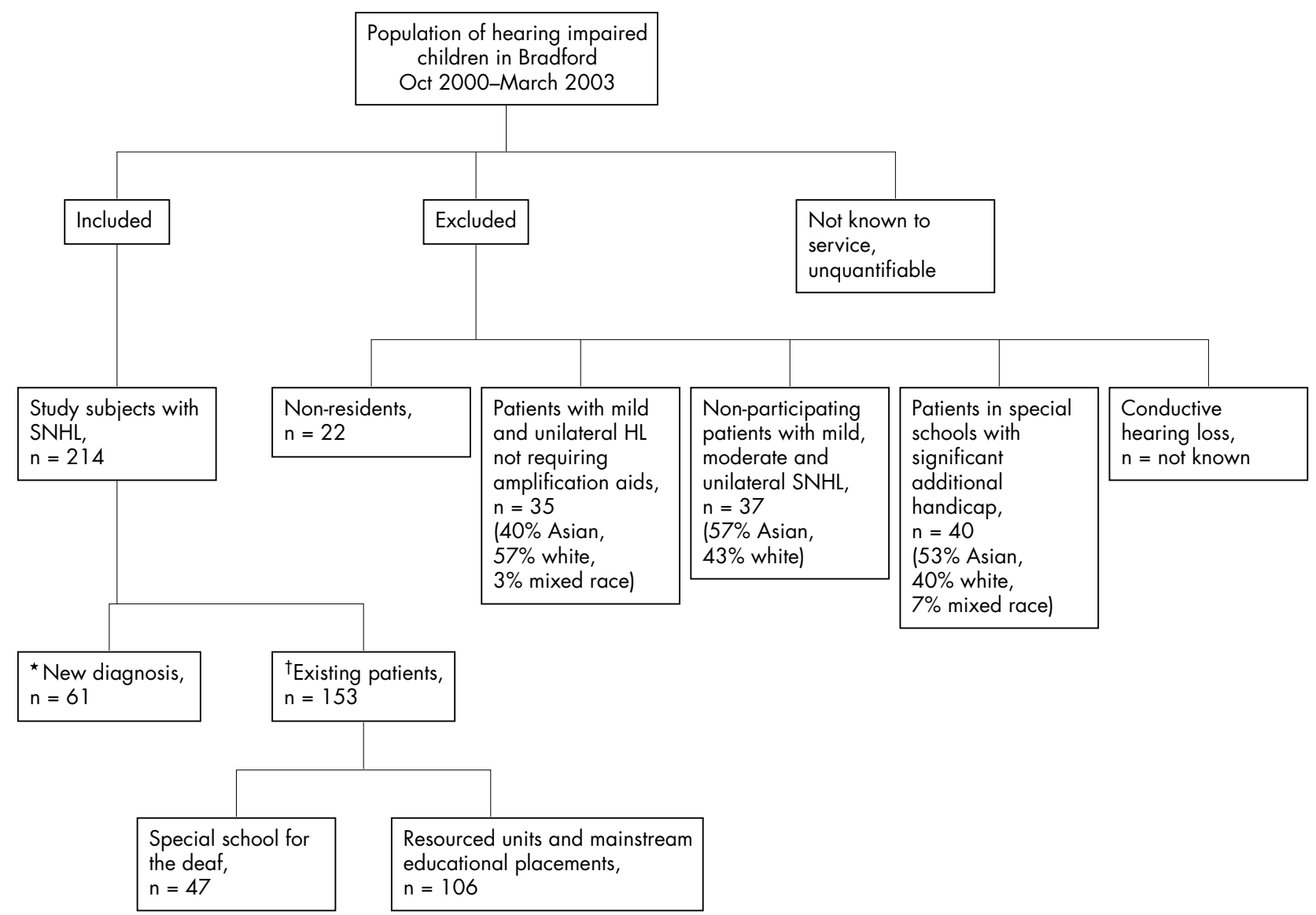

Figure 2 Distribution of hearing impaired children in Bradford during the study period. SNHL, sensorineural hearing loss; HL, hearing loss. *New diagnosis: any child newly confirmed to have a sensorineural hearing loss by the audiological scientists. †Existing patients: any child with significant sensorineural hearing loss fitted with hearing aids. These include those whose hearing loss was severe enough for them to be in a special school for the deaf. Those who were partially deaf and required amplification aids and peripatetic support were in a resourced unit for hearing impaired pupils or mainstream nurseries and schools.

\section{Risk factors}

Parental consanguinity and family history of deafness were both statistically significantly more common in Pakistani families compared to white families (table 2). Previous meningitis was significantly more common in white children. None of the other differences reached statistical significance apart from the "other" category, which included children with syndromic abnormalities associated with deafness and congenital infections.

There were no significant differences in the type or degree of hearing loss between our comparison groups (table 3). The number of children in Pakistani families was statistically significantly higher than in white families (table 4).

\section{Use of hospital services}

Table 5 shows the proportions of Pakistani and white families taking up specified services. Notably more Pakistani families were likely to take up genetic counselling $(50.0 \% \vee 35.0 \%)$ and cochlear implantation $(64.7 \% \vee 25.0 \%)$, the latter difference being statistically significant $(p=0.040)$. The uptake of services was not influenced by whether the children were diagnosed "early" or "late" (data available on request).

\section{DISCUSSION}

This study failed to observe any substantial differences in the pattern of uptake of relevant hospital services between Pakistani and white families with deaf children.

\begin{tabular}{|c|c|c|c|c|}
\hline Variable & Category & $\begin{array}{l}\text { Pakistani (\%) } \\
n=140\end{array}$ & $\begin{array}{l}\text { White (\%) } \\
n=67\end{array}$ & $\begin{array}{l}\text { Total (\%) } \\
n=214\end{array}$ \\
\hline \multirow[t]{2}{*}{ Patient type } & New diagnosis & $40(28.6)$ & $19(28.4)$ & $59(28.5)$ \\
\hline & Existing patient & 100 (71.4) & $48(71.6)$ & 148 (71.5) \\
\hline \multirow[t]{2}{*}{ Gender } & Male & $68(48.6)$ & $26(38.8)$ & $94(54.6)$ \\
\hline & Female & 72 (51.4) & $41(61.2)$ & $113(45.4)$ \\
\hline \multirow[t]{3}{*}{ Ethnicity } & Pakistani & & & $140(65.4)$ \\
\hline & White & & & $67(31.3)$ \\
\hline & Other ${ }^{*}$ & & & $7(3.3)$ \\
\hline \multirow{2}{*}{$\begin{array}{l}\text { Age at data } \\
\text { collection }\end{array}$} & Preschool $(<4.5$ y) & $36(25.7)$ & $12(17.9)$ & $48(23.2)$ \\
\hline & School age $(>4.5 y)$ & $104(74.3)$ & $55(82.1)$ & $159(76.8)$ \\
\hline
\end{tabular}


Table 2 A comparison of Pakistani and white families by risk factors

\begin{tabular}{|c|c|c|c|c|}
\hline Risk factor & $\begin{array}{l}\text { Pakistani (\%) } \\
n=140\end{array}$ & $\begin{array}{l}\text { White (\%) } \\
n=67\end{array}$ & $\begin{array}{l}\text { Total }(\%) \ddagger \\
\mathbf{n}=\mathbf{2 0 7}\end{array}$ & $p$ value \\
\hline Late diagnosis* & $93(66.4)$ & $49(73.1)$ & $142(68.6)$ & 0.437 \\
\hline Consanguinity $†$ & $121(86.4)$ & $1(1.5)$ & $122(58.9)$ & $<0.001$ \\
\hline $\mathrm{FH}$ of deafness & $93(66.4)$ & $26(38.8)$ & $119(57.5)$ & $<0.001$ \\
\hline Meningitis & $2(1.4)$ & $9(13.4)$ & $11(5.3)$ & $<0.001$ \\
\hline $\mathrm{NICU} / \mathrm{SCBU}$ & $7(5.0)$ & $6(9.0)$ & $13(6.3)$ & 0.154 \\
\hline $\begin{array}{l}\text { Syndromes/congenital } \\
\text { infections }\end{array}$ & $7(5.0)$ & $9(13.4)$ & $16(7.7)$ & 0.047 \\
\hline No risk factors & $31(22.1)$ & $17(25.4)$ & $48(23.2)$ & \\
\hline \multicolumn{5}{|c|}{$\begin{array}{l}\text { FH, family history; NICU, neonatal intensive care unit; SCBU, special care baby unit. } \\
\text { *Detail not known for one Pakistani family. } \\
\text { †Detail not known for } 6 \text { (4.3\%) Pakistani families. } \\
\ddagger \text { Total of Pakistani and white families. }\end{array}$} \\
\hline
\end{tabular}

This finding is unlikely to have been influenced by differences in the degree of hearing loss. Our comparison groups did not differ according to either the type or degree of deafness. Degrees of hearing loss are probably related to the differences in aetiological patterns of sensorineural deafness, but are not necessarily significant predictors of the use of health services.

In order to reduce the possibility of selection bias in our study sample, subjects were selected from the broader population of children with hearing impairment who were living in Bradford, and a clear definition of inclusion was adhered to. Our findings are therefore restricted to that group but do apply to the majority of this population. This study included a fairly large sample of families, giving us confidence in the findings, but whether the conclusions are generalisable directly to other areas, is of course debatable. Further studies comparing populations with different ethnic profiles are needed to confirm the observation that ethnicity does not appear to be a barrier to the uptake of services for families with deaf children.

One service which anecdotally was thought to have been refused by the Pakistani community was genetic counselling. The high prevalence of autosomal recessive inherited deafness has been associated with the high level of consanguineous marriages, family history of deafness, and large families among Asian populations. ${ }^{915}{ }^{16}$ It is frequently suggested that this service should be considered in reducing the prevalence of deafness. This study has shown that Pakistani families in Bradford have not markedly declined genetic counselling by culturally sensitive counsellors with more insight into the particular concerns and fears of the Asian deaf families. There was better acceptance of this service when explanations were provided in a manner that was sensitive to their linguistic and cultural differences. It appears that acceptance of genetic counselling by this Pakistani community has little impact on its high level of hereditary deafness. The reasons for this are complex and have not been extensively researched.

Non-white families in Bradford have a high rate of illiteracy. ${ }^{17}$ Many of the Pakistani families speak little or no English and have communication difficulties. These parents are given information about the causes of deafness, the importance of early detection of hearing loss, and use of hearing aids using Urdu/Punjabi speaking liaison workers and genetic counsellors so that they could understand and accept early intervention and habilitation programmes. There has been relatively little work done to explore how the information is used by parents with poor literacy skills and for whom English is not their first language. This is important as non-directive counselling is very dependent on the educational background and level of understanding and opinions of these families for whom this service is relevant. Poor literacy skills may limit their ability to understand genetically inherited conditions and related information. Any pre-existing belief will also prevent these families from acting on the information.

There has to be recognition that some families prefer to have deaf children. No data were available describing which families prefer to have deaf children, and we are therefore unable to comment on whether there is a difference between Pakistani and white families. Asian deaf community and health professionals often have different views and beliefs about genetics because deafness can be viewed from different perspectives. ${ }^{2}$ The deaf community, including those from the Asian population, are often sensitive to the threats to their communities; for example, this reaction has been shown in the resistance to cochlear implantation and genetic counselling. ${ }^{18}{ }^{19}$ It has been suggested that deaf persons ought to be

Table 3 The type and degree of hearing loss by ethnic group

\begin{tabular}{|c|c|c|c|c|}
\hline Type of hearing loss & $\begin{array}{l}\text { Pakistani (\%) } \\
n=140\end{array}$ & $\begin{array}{l}\text { White (\%) } \\
n=67\end{array}$ & $\begin{array}{l}\text { Total }(\%) \\
n=207\end{array}$ & $\mathrm{p}$ value \\
\hline Bilateral & $119(85.0)$ & $50(74.6)$ & $169(81.6)$ & \multirow{12}{*}{0.154} \\
\hline Unilateral & $4(2.9)$ & $3(4.5)$ & $7(3.4)$ & \\
\hline Bilateral mixed & $15(10.7)$ & $14(20.9)$ & $29(14.0)$ & \\
\hline Unilateral mixed & $2(1.4)$ & 0 & $2(1.0)$ & \\
\hline Degree of hearing loss & & & & \\
\hline Mild $(20-40 \mathrm{dbHL})$ & $5(3.6)$ & $5(7.5)$ & $10(4.8)$ & \\
\hline Mild/moderate (asymmetric) & $3(2.1)$ & $5(7.5)$ & $8(3.9)$ & \\
\hline Mild/severe (asymmetric) & 0 & $1(1.5)$ & $1(0.5)$ & \\
\hline Moderate (41-70 dbHL) & $59(42.1)$ & $23(34.3)$ & $82(39.6)$ & \\
\hline Moderate/severe (asymmetric) & $5(3.6)$ & $5(7.5)$ & $10(4.8)$ & \\
\hline Severe (71-95 dbHL) & $22(15.7)$ & $8(11.9)$ & $30(14.5)$ & \\
\hline Profound (>95 dbHL) & 46 (32.9) & $20(29.9)$ & 66 (31.9) & \\
\hline
\end{tabular}

*Fisher's exact test.

$\dagger \chi^{2}$ test for trend. 
Table 4 Comparison of birth order in Pakistani and white families

\begin{tabular}{llllll}
\hline Birth order & $\mathbf{1}$ & $\mathbf{2}$ & $\mathbf{3}$ & $\mathbf{4}$ & $\mathbf{5}$ \\
\hline Total, $\mathrm{n}=207$ & 67 & 53 & 44 & 22 & 21 \\
Pakistani $(\%), \mathrm{n}=140$ & $40(28.6)$ & $31(22.1)$ & $34(24.3)$ & $17(12.1)$ & $18(12.9)$ \\
White $(\%), \mathrm{n}=67$ & $27(40.3)$ & $22(32.8)$ & $10(14.9)$ & $5(7.5)$ & $3(4.5)$ \\
\hline
\end{tabular}

trained as genetic counsellors to provide appropriate counselling to deaf families. ${ }^{18}$ There is a need for education within the deaf community about genetics. There is an even greater need for well informed teachers and workers who are sensitive to the cultural background of the families they support and to promote their needs rather than a societal goal alone. Further research into in-depth understanding of specific families' circumstances will help inform early intervention practices.

The best outcomes are attained when families become involved and when intervention is initiated early. ${ }^{20}$ The early provision of intervention may provide families the support they need to become actively involved in promoting the child's linguistic development. A previous study ${ }^{21}$ has shown that families' use of health services was not related to ethnicity or socioeconomic status, where in fact children from minority ethnic groups were able to access primary care but less likely to be referred to secondary care. Calderon ${ }^{22}$ reported that socioeconomic status was a marginally significant predictor of maternal communication. She hypothesises that mothers from higher socioeconomic status may have access to more resources that support their development of communicative skills with the child. Social services should be involved at an early stage, to help improve support services such as transportation and completion of benefit forms for lower socioeconomic status families, to facilitate their readiness to use services.

There is emerging evidence ${ }^{720}$ that the newborn hearing screening programme is an effective screening programme, delivering a more uniform service with better outcomes. Any improvement in service provision will need to include universal newborn screening, parental education and involvement, appropriate diagnostic testing, education of healthcare professionals to have an appreciation and recognition of the linguistic, cultural, and religious differences of ethnic minority families, and better access to culturally sensitive deaf aware counsellors. This will be assisted by information for parents about aetiological investigations, which is currently in development by the National Deaf Children Society.

It is imperative that services of high quality are available, attractive, accessible, and appropriate for all ethnic groups in

Table 5 Hospital services and their uptake for Pakistani and white families

\begin{tabular}{|c|c|c|c|c|c|c|c|}
\hline & \multicolumn{2}{|l|}{ Total } & \multicolumn{2}{|c|}{ Pakistani } & \multicolumn{2}{|c|}{ White } & \multirow[b]{2}{*}{$p$ value } \\
\hline & $n$ & $\%$ & $n$ & $\%$ & $\mathrm{n}$ & $\%$ & \\
\hline \multicolumn{8}{|l|}{ Genetics } \\
\hline Taken up & 77 & 45.8 & 63 & 50.0 & 14 & 35.0 & \\
\hline Declined & 75 & 44.6 & 54 & 42.9 & 21 & 52.5 & \\
\hline Referred $^{*}$ & 14 & 8.3 & 9 & 7.1 & 5 & 12.5 & \\
\hline Total & 168 & 100.0 & 126 & 100.0 & 40 & 100.0 & $0.209 \dagger$ \\
\hline \multicolumn{8}{|l|}{ Aetio $\mathbf{~ x ~}$} \\
\hline Taken up & 93 & 58.1 & 67 & 54.9 & 26 & 68.4 & \\
\hline Declined & 67 & 41.9 & 55 & 45.1 & 12 & 31.6 & \\
\hline Total & 160 & 100.0 & 122 & 100.0 & 38 & 100.0 & $0.141 \dagger$ \\
\hline \multicolumn{8}{|c|}{ Ophthalmic } \\
\hline Taken up & 54 & 49.5 & 43 & 47.8 & 11 & 57.9 & \\
\hline Declined & 34 & 31.2 & 28 & 31.1 & 6 & 31.6 & \\
\hline Referred $^{*}$ & 21 & 19.3 & 19 & 21.1 & 2 & 10.5 & \\
\hline Total & 109 & 100.0 & 90 & 100.0 & 19 & 100.0 & $0.539+$ \\
\hline \multicolumn{8}{|c|}{ Cochlear implant } \\
\hline Taken up & 13 & 52.0 & 11 & 64.7 & 2 & 25.0 & \\
\hline Declined & 9 & 36.0 & 3 & 17.6 & 6 & 75.0 & \\
\hline Referred* & 3 & 12.0 & 3 & 17.6 & 0 & 0.0 & \\
\hline Total & 25 & 100.0 & 17 & 100.0 & 8 & 100.0 & $0.040 \ddagger$ \\
\hline \multicolumn{8}{|l|}{ Audiology } \\
\hline Taken up & 206 & 99.5 & 140 & 100.0 & 66 & 98.5 & \\
\hline Declined & 1 & 0.5 & 0 & 0.0 & 1 & 1.5 & \\
\hline Referred $^{*}$ & 0 & 0.0 & 0 & 0.0 & 0 & 0.0 & \\
\hline Total & 207 & 100.0 & 140 & 100.0 & 67 & 100.0 & $0.324 \ddagger$ \\
\hline \multicolumn{8}{|c|}{ Ear, nose, throat } \\
\hline Taken up & 115 & 92.7 & 74 & 92.5 & 41 & 93.2 & \\
\hline Declined & 3 & 2.4 & 3 & 3.8 & 0 & 0.0 & \\
\hline Referred $^{*}$ & 6 & 4.8 & 3 & 3.8 & 3 & 6.8 & \\
\hline Total & 124 & 100.0 & 80 & 100.0 & 44 & 100.0 & $0.464 \ddagger$ \\
\hline
\end{tabular}




\section{What is already known on this topic}

- Previous studies have reported barriers to access of services for deaf minority ethnic families, with poorer uptake of services compared to the general population

order that problems are detected early on. The concept of service delivery with a "colour blind" attitude ("we treat everyone the same") cannot give satisfactory results as it overlooks significant differences in the way people of ethnic minority backgrounds are likely to behave and seek help for their families. Strategies for effective and successful service provisions need to include the use of qualified deaf aware bilingual interpreters and counsellors. There will be considerable policy implications, as in order to provide effective intervention, the management strategies needed may result in changes in practice.

Our study showed a similar pattern of hospital service uptake for Pakistani and white families. Bradford's deaf Asian families are using relevant hospital services and ethnic differences did not seem to be a barrier to access. This observation probably reflects this city's recognition of a culturally appropriate approach to service delivery and commitment to put this into practice.

\section{ACKNOWLEDGEMENTS}

We are grateful to Professor Jenny Hewison for her valuable advice and Dr Mary Rudolf for her comments on the manuscript. Special thanks are extended to Peter Waring for his technical assistance with setting up the database, Judith Holdsworth for her patience with data entry, and Andy Scally for initial discussion about statistical analysis.

\section{Authors' affiliations}

S Y Yoong, St Luke's Hospital, Bradford, UK

R Feltbower, P A McKinney, Paediatric Epidemiology Group, University of Leeds, UK

N Spencer, School of Postgraduate Medical Education, University of Warwick, UK

Competing interests: none declared

\section{REFERENCES}

1 Ahmad W, Darr A, Jones L, et al. Deafness and ethnicity: services, policy and politics. Bristol: The Policy Press, 1998.

2 Chamba R, Ahmad W, Jones L. Improving services for Asian deaf children: parents' and professionals' perspectives. Bristol: The Policy Press, 1998.

3 Jones L, Atkin K, Ahmad W. Supporting Asian deaf young people and their families: the role of professionals and services. Disab Soc $2001 ; 16: 51-70$.

\section{What this study adds}

- This study looked specifically at uptake of relevant hospital services in a multiethnic city with a high prevalence of deafness

- Findings did not support the widely accepted view that deaf Asian families are poor users of secondary service

- The reasons are not clear but could be due to local recognition and implementation of a culturally appropriate approach to service delivery.

4 Lumb KM. Prevalence of hearing loss in children of Asian origin. Proceedings of the Scientific meeting of the British Association of Audiological Physicians and the Community Paediatric Group. 1981:60-5.

5 Parry G. Aetiology and prevalence of childhood hearing impairment in Bradford. Audiens 1995;20:25-9.

6 Corry PC. Intellectual disability and cerebral palsy in the UK community. Community Genet 2002;5:201-4

7 Davis A, Bamford J, Wilson I, et al. A critical review of the role of neonatal hearing screening in the detection of congenital hearing impairment. Health Technol Assess 1997;1:1-176.

8 White A. Social focus in brief: ethnicity. London: Office for National Statistics, 2002 (available from www.statistics.gov.uk/statbase/ Product.asp?vlnk=9763).

9 Zakzouk S. Consanguinity and hearing impairment in developing countries: a custom to be discouraged. J Laryngol Otol 2002;116:811-16.

10 British Society of Audiology. British Society of Audiology Recommendation: descriptors for pure tone audiograms. Br J Audiol 1988;22:123.

11 American Academy of Pediatrics Joint Committee on Infant Hearing. Joint Committee on Infant Hearing 1994 Position Statement. Pediatrics 1995;95:152-6.

12 Fortnum HM. Hearing impairment after bacterial meningitis; a review. Arch Dis Child 1992;67:1128-33.

13 British Association of Audiological Physicians. Best practice guidelines for aetiological investigation of hearing loss. London: British Association of Audiological Physicians, 2002 (available from www.baap.org.uk).

14 Bamiou DE, MacArdle B, Bitner-Glinzicz M, et al. Aetiological investigation of hearing loss in childhood: a review. Clin Otolaryngol 2000;25:98-106.

15 Naeem Z, Newton V. The prevalence of sensorineural hearing loss in Asian children. Br J Audiol 1996;30:332-40.

16 Darr A, Modell B. The frequency of consanguineous marriage among British Pakistanis. J Med Genet 1988;25:186-90.

17 Tuffnell D, Nuttall K, Raistrick J. Use of translated written material to communicate with non-English speaking patients. BMJ 1994;309:992.

18 Middleton A, Hewison J, Mueller RF. Attitudes of deaf adults toward genetic testing for hereditary deafness. Am J Hum Genet 1998;63:1175-80.

19 Tucker BP. Deaf culture, cochlear implants and elective disability. Hastings Cent Rep 1998;28:6-14

20 Yoshinaga-Itano C, Coulter D, Thomson V. Infant hearing impairment and universal hearing screening. The Colorado Newborn Hearing Screening Project: Effects on speech and language development for children with hearing loss. J Perinatol 2000;20:S132-7.

21 Saxena S, Eliahoo J, Majeed A. Socioeconomic and ethnic group differences in self reported health status and use of health services by children and young people in England; cross sectional study. BMJ 2002;325:520-3.

22 Calderon R. Parental involvement in deaf children's education programs as a predictor of child's language, early reading and social emotional development. J Deaf Stud Deaf Educ 2000;5:140-55. 